\title{
How family members of mentally ill offenders experience the internment measure and (forensic) psychiatric treatment in Belgium: A qualitative study
}

\section{Abstract}

Mentally ill offenders in Belgium can be subjected to mandated care under an "internment measure" if they are viewed as a danger to society. This study investigated how family members of mentally ill offenders experience this internment measure and view the (forensic) psychiatric treatment of their relative. Semi-structured interviews were conducted with 24 relatives and analysed using Nvivo 11. Six different themes emerged: (1) The criminal offence and the internment measure as an additional stigma, (2) Ambivalent feelings towards the judicial system, (3) Prison is not the right place to be, (4) Mental health support as an answer to problems, (5) Fight a losing battle, and (6) While there is life there is hope. The experiences of family members indicate the need for improved treatment guidelines that allow earlier compulsory interventions to prevent crime and preferential admission to (forensic) psychiatric facilities rather than prisons. In addition, family members expressed the need for better communication from mental health professionals and the judicial system during the process and greater availability of peer support.

\section{Key words}

Mentally ill offenders, family experiences, internment measure 


\section{Introduction}

About $3 \%$ to $10 \%$ of mentally ill persons commit criminal offences due to their illness (Peterson, Skeem, Kennealy, Bray, \& Zvonkovic, 2014). In most Western countries, mentally ill offenders may be judged as 'not criminally responsible' for their actions and subject to specific criminal justice legislations (Abracen, Gallo, Looman, \& Goodwill, 2015; Sheehy et al., 2016). In Belgium, such mentally ill offenders are placed under an "internment measure" as they are - at the same time - seen as a danger for society ("criminals") but also as persons who need treatment and care ("patients") (Vandevelde et al., 2011). The internment measure is defined as "a safety measure to protect society and that simultaneously aims to ensure that the mentally ill offender is provided with the care his/her condition requires in view of his/her reintegration into society" (Heimans, Vander Beken, \& Schipaanboord, 2015, p. 1051, translation by the authors). It is an indeterminate measure that, at the time of the study, was decided by a multidisciplinary commission, the Commission of Protection of Society, chaired by a judge (Bal \& Koenraadt, 2000; Vandevelde et al., 2011). Since 1 October 2016 a new Law (5 May 2014) has come into force which replaced the Commission of Protection of Society into Chambers of Protection of Society. The new Law states that mentally ill offenders can only be subjected to an internment measure if their criminal offence harms the psychical and psychological integrity of a third party, if they have a mental illness at the time of the offence and if there is a danger to commit new offences. The Law aims at providing mentally ill persons with opportunities to acquire appropriate mental health care leading to successful integration in society (Vander Beken, Heimans, \& Schipaanboord, 2016). 
Mentally ill offenders are not held responsible for the crimes they have committed and are regarded as persons in need of treatment. Therefore the proctection of society and the basic rights of mentally ill persons to receive adequate psychiatric treatment are equal aspects within the internment measure (Meysman, 2016). However, mentally ill offenders are often incarcerated in correctional settings (e.g. prison), for a lengthy period of time, because places in (forensic) psychiatric settings are scarce and often unavailable (Abracen et al., 2015; Melamed, 2010; Peterson et al., 2014; Sheehy et al., 2016; Bal \& Koenraadt, 2000; Vandevelde et al., 2011). Belgium, as well as other European countries (e.g. France, United Kingdom, Romania, Poland, Hungary etc.), have been sentenced several times by the European Court of Human Rights (ECHR) for violating the rights of mentally ill offenders. Until today and despite the new Law, more than 750 mentally ill offenders (K. Seynnaeve, personal communication, March $15,2017)$ who are subjected to the internment measure are still living in prison without appropriate care (Meysman, 2016).

Mentally ill offenders frequently report that the internment measure (including the frequent incarceration) and the lack of mental health care are painful and burdensome (De Smet et al., 2014; Morgan et al., 2012; Sarteschi, 2013; Ting To et al., 2014). Further, some studies indicate that family members are also burdened by the internment measure, the mental illness, and the criminal acts of their mentally ill relative (Rowaert et al., 2016; Tsang, Pearson \& Yuen, 2002). They experience double stigmatisation as their mentally ill relative is seen as both 'mad and bad' (Tsang et al., 2002; Tsang, Tam, Chan, \& Chang, 2003) and frequently require professional support themselves (Gavois, Paulsson, \& Fridlund, 2006; Jankovic et al., 2011; Muralidharan, Lucksted, Medoff, Juan Fang, \& Dixon, 2014; Nordström, Kullgren, \& Dahlgren, 2006). 
Moreover, close family members play primary roles in supporting the re-entry of their relative from prison or psychiatric hospital back into society and in enhancing the wellbeing of both the mentally ill relative and their family network (Hairston, 2015; McKay Comfort, Lindquist, \& Bir, 2016; Pearson, \& Tsang, 2004).

Few studies have reported on these burdens of family members, the limited contact between family members and forensic mental health professionals, and family members' need for involvement in the mental health care of their relative (Bolkan et al., 2013; Hayes, Hawthorne, Farhall, O'Hanlon, \& Harvey, 2015; Rowaert et al., 2016). Therefore, the aim of this study is to investigate how family members experience the mental illness, the internment measure, and the (forensic) psychiatric treatment of their relative.

\section{Method}

\subsection{Procedure}

To recruit family members of mentally ill offenders, an information leaflet was spread in several settings in Flanders (e.g. psychiatric facilities, prisons, non-profit organizations for family members of persons with a mental illness, and ambulatory mental health services). Forty-eight persons agreed to participate in the study, resulting in 26 interviews that were conducted from February to June 2015. The following inclusion criteria were used: having a relative with a current or past internment measure and age 18 or older. Mentally ill offenders $(n=2)$, family of people with nonforensic mandated care $(n=11)$, and family of convicted persons $(n=3)$ were not 
included. Further, six persons were lost to follow-up $(n=5)$ or the contact address was incorrect $(n=1)$. Two of the 26 persons interviewed were volunteers in an organization to support mentally ill offenders in prison (cf. Figure 1) and were excluded from the analysis. In total, 24 interviews were analysed.

All participants provided informed consent for publication of their interview responses. The study was approved by the Ethics Committee of the Ghent University Hospital (EC decision: B670201422070).

[Figure 1 approximately here]

\subsection{Participants}

The mean age of the participants was 58.8 years (SD: 11.3, range: 27 to $80 \mathrm{yrs).} \mathrm{The}$ sample consisted primarily of mothers $(n=13 ; 48.1 \%)$ and fathers $(n=6 ; 22.2 \%$, of which 3 were interviewed together with their spouse). Other participants included siblings $(n=4 ; 14.9 \%)$, daughters $(n=2 ; 7.4 \%)$ and uncles and aunts $(n=2 ; 7.4 \%)$.

At the time of the interviews, the relatives of the families being interviewed were staying at different locations. Some of the mentally ill offenders lived in residential psychiatric care $(n=13 ; 54.2 \%)$, others in prison $(n=5 ; 20.8 \%)$, or in a community-based setting $(n=6 ; 25 \%)$. In $19(79 \%)$ of the 24 cases, the internment measure was still ongoing. Family members reported the following psychiatric conditions of their relatives: psychotic disorders $(n=18)$, intellectual disability $(n=1)$, autism $(n=5)$, bipolar disorder $(n=1)$, personality disorder $(n=4)$, and unknown $(n=1)$. Mean age of the mentally ill 
offenders was 41 years (SD: 12.3, range: 27 to $77 \mathrm{yrs}$.). Most of the mentally ill offenders were male $(n=23 ; 88 \%)$.

\subsection{Data collection}

A topic list based on a literature review and a theoretical model about family burden were used to conduct the interviews (Rowaert et al., 2016; Tsang et al., 2002). The topics related to the experiences of family members regarding the psychiatric history of their relative, the legal proceedings and the internment measure they were confronted with. Furthermore the topics included the impact of the psychiatric problems and the internment measure on family members. To end the interview, attention was paid to coping strategies, strengths of family members and future perspectives. All interviews (except one because of refusal) were audiotaped. Interviews lasted on average 2 hours (range: 0.5 and 3.5 hours). Notes were taken of the interview that was not audiotaped.

\subsection{Data analysis}

Interviews were transcribed verbatim and together with the notes of one interview, thematically analysed in Nvivo 11 (QSR International Pty Ltd., 2015). Thematic analysis is been described as: "a method for identifying, analysing, and reporting patterns (themes) within data. It minimally organises and describes your data set in (rich) detail' (Braun \& Clarke, 2006, p.6). Using a thematic analysis offers the possibility to "give voice" to the participants and "involves carving out unacknowledged pieces of 
narrative evidence that we select, edit, and deploy to border our arguments" (Fine, 2002, p.218).

Because research about family members of mentally ill offenders (especially when subjected to an interment measure) is only scantly available, we have conducted the analysis starting from an inductive approach to derive themes closely linked to the data. This provided us with a rich description and gave us an idea about the experiences of family members of mentally ill offenders. Simultaneously, a deductive process was used, as it was important to know how the topics found in our study were comparable to findings in previous research studies (Braun, \& Clarke, 2006; Braun, \& Clarke, 2012; Mortelmans, 2011; Rowaert et al., 2016). Furthermore within this study we aimed to investigate sources of strength and coping strategies of family members, as this was not yet studied before.

The thematic analysis followed the six steps suggested by Braun and Clarke (2006; 2012). Phase 1 involves familiarisation with the data by reading the transcriptions several times. The data were first analysed by two master-level students in Special Needs Education and resulted in a tree structure, which was further discussed with the first author of this paper. This was the start of an ongoing reflexive dialogue typical for thematic analysis. The first author re-analysed the data using an open coding process and generated initial codes (e.g. emotions, behaviours, prison, forensic psychiatry ...) closely linked to what family members experience when confronted with a mental illness and an internment measure of a relative (inductive approach; phase 2). In phase 3 , the first author searched for themes that combine codes generated in phase 2 and compared this tree structure to the themes generated by the two students. 
Consequently themes were linked to others, resulting in broader themes such as judicial procedure, internment measure, perceptions ... Phase 4 reviewed the themes of phase 3 to come to an accurate reflection of the content of the data set. In phase 5 , discussions and meetings with the 3 co-authors about the themes found in phase 3 and 4, identified 6 main themes regarding family's experiences: (1) The criminal offence and the internment measure as an additional stigma, (2) Ambivalent feelings towards the judicial system, (3) Prison is not the right place to be, (4) Mental health support as an answer to problems, (5) Fight a losing battle, and (6) While there is life there is hope. In phase 6 , the results were written up. 


\section{Results}

\subsection{Theme 1: The criminal offence and the internment measure as an additional stigma}

Family members mentioned that the internment measure is perceived as taboo by their mentally ill relative and by themselves, leading to an additional stigma for both. Mentally ill offenders are seen by society rather as criminals than as patients with mental health needs. This is a source of stress for both the mentally ill offender and their families as these labels cause an intricate search for appropriate mental health treatment. Moreover because families perceive that many professionals often hesitate to admit a mentally ill offender to their psychiatric hospital because of their criminal label.

"That's taboo. There exists a very negative image about psychiatry but the internment that is an additional and double taboo..... they are stigmatised, they are more seen as criminals and consequently treated that way. Once they have being labelled, it is very hard to detach the illness from the label." (Mother)

Family members often experience feelings of guilt. Particularly, parents expressed feelings of having failed in raising their children. Furthermore, they often feel ashamed when confronted with the dual stigma of the mental illness and criminal offence.

"We first thought: it might be our fault. As this is the first thing parents think. They blame themselves for what is happening." (Mother) 
"You have something like: I have to bite my tongue, because if I am going to say something about it, I will not be able to stop and then they will know it all. Yes, I have felt a lot of shame." (Daughter)

The family members felt socially isolated or discriminated against by society, partly because friends were shocked by the detention and did not respond appropriately to it. As a result, they became more hard-hearted and bitter over time, and some participants said they avoided talking about the situation or their problems.

"Telling to friends was difficult. They were shocked and did not know how to behave and what to say. You notice that it is for them partly unknown." (Brother)

Other family members, however, reported that sharing their stories with others helped them to better cope with the situation.

"I have never, never hidden it. [...] I thought if I have to conceal it, I cannot handle it anymore. It was all, it was overwhelming for me. And if you then have to tell lies to everyone. I find it difficult. Subsequently they will notice me lying." (Sister)

\subsection{Theme 2: Ambivalent feelings towards the judicial system}

Family members had ambivalent feelings about the Commission of the Protection of Society. The lack of information about when and how the case of their mentally ill relative was handled led to frustrations, particularly when the family members had no influence on the decision process. However, some family members felt that being 
heard after contacting the Chairman of the Commission led to better care for their mentally ill relative.

"Everyone is talking about the Commission and about how they do not take into account what we are saying. Well, I experienced it differently. Not in the beginning, but at the time I have written that letter, they have taken it into account. And that is why our son could go back to the psychiatric hospital that he previously was admitted to." (Mother and father)

Despite this ambivalence, many family members believe that the internment measure is the starting point of change for their relative, eventually leading to adequate treatment of the mental illness. Many mentally ill persons follow a long-term trajectory within forensic facilities. Eventually, most are admitted to psychiatric hospitals or permitted to live independently with ambulatory help, which aids in their reintegration back into society.

"Now I say openly, I think that the internment was his salvation. Otherwise we would not be where we are today." (Mother)

About one third of the family members had hired a legal aid counsellor to support their relative's case in court. In their opinion, however, most counsellors lacked sufficient knowledge about mental illness, the needs of their mentally ill relative, and current mental health status. The counsellors were seen as particularly helpful when they succeeded in getting their relative out of prison and into the care of a psychiatric clinic. However, they were generally regarded as quite expensive, often leading to a financial 
burden.

"Also the lawyers and the legal aid counsellors should be educated about mental health problems. They all know little about it." (Mother)

"A few weeks ago his lawyer suddenly contacted us and said that our son had to appear in court again and that he managed to get him into the new psychiatric hospital in Ghent. [...] In the past we have paid all the lawyers which sometimes in the long run means that people have to sell their house and still nothing changes." (Mother and father)

As part of the internment measure, some mentally ill offenders are no longer allowed to manage their financial resources and are placed under financial administration. Most of the time, an independent lawyer or sometimes a family member will be placed in charge of the offender's financial affairs. In case of a lawyer, the family members may be left unaware of the financial situation of their relative. When family members are responsible, however, they may feel unqualified and unprepared to take on the role of financial administrator.

"I questioned certain costs. A yearly visit to prison was 75 euro for just going around the corner, as it was really close by. My brother had to pay for a visit of a complete stranger, without any support from a confidant." (Brother)

“I'm his financial administrator. Actually I have never received any explanation of how I have to do it. It is something that I don't understand very good." (Mother) 


\subsection{Theme 3: Prison is not the right place to be}

Mentally ill offenders are often incarcerated in prison due to the internment measure. Prison is regarded by the family members as inappropriate as the offender will not receive adequate support and treatment. Even if some care is provided, it is often perceived to be limited to psychopharmacological management. Further, the prison staff often lack competence in dealing with mentally ill persons. Family members feel that their relative is treated more as a criminal than as a mentally ill person. They also believe that some prison staff misuse their power as they do not know how to interact with mentally ill offenders. Therefore, family members report that prison employees should be educated about mental illnesses and trained on how to interact with persons with mental illnesses. Finally, the family members also experience the procedures required to visit their relative in prison as difficult and burdensome.

"The only thing that happened was prescribing medication, medication, medication. That's it. It's little less than scandalous. And what happened next? It didn't help or it was too little to stop the psychoses. They gave him more heavy medication and at the end nothing helped anymore." (Father)

"A visit to prison is on the one hand a mix of: 'he sees us and he is happy', but on the other hand we feel like: 'See us sitting here'. [...] And then those moments of: 'We almost have to go, we need to run down the conversation.' Subsequently they have to stand again one by one at the door. And then again, the procedure to go back outside, where you first have to pick up your passport and ask for your belt and jacket. 
Afterwards you are feeling like: 'What is this?' After a while you don't like to go there anymore, but still I have to, because I know it is to support my brother." (Brother)

As family members regard prison as inappropriate for their relative, most use every possible means (e.g., contacting different mental health institutions) to get their relative out of prison and into more appropriate mental health care facilities.

"At one moment, I begun working and searching until I have found somebody, a psychologist. I have put pressure on him to find an organization for my son and to get him out of prison." (Mother)

\subsection{Theme 4: Mental health support as answer to the problems}

Most mentally ill offenders and their family members in this study had a longstanding history with the mental health care system before the criminal offence. Their relationship with mental health professionals was often difficult because they did not receive sufficient information about the condition and its treatment, and had little involvement in the treatment of their mentally ill relative. This stems partly because from medical confidentiality of the professionals.

"That is such a pity, that you as a parent are so little involved. And that you see things going wrong, but you cannot do anything. [...] He shall always be our son for who we intend the best. And as a parent you are locked out." (Father and mother)

Consequently, many family members searched for relevant information on the internet 
or in books about the medical condition of their relative and the internment measure. Some also participated in activities organized by non-profit organization for family members of mentally ill persons to gather more information about the illness or the judicial system. If mental health professionals did provide information, it was often regarded as incomplete or incomprehensible "physician talk". Further, family members reported insufficient support from mental health professionals in their search for daily social activities and housing accommodations for the mentally ill relative.

"I have always searched for information, because it are tempestuous moments you go through and that leaves a lasting impression. [...] You always search for the next steps that are going to happen or when it is going to end." (Mother)

"Eventually the patients themselves or we, the family, has to do it. Social housing, I have submitted the application. I've went two, three times to the social housing company." (Mother and father)

Finally, although they were relieved that their mentally ill relative was admitted to a psychiatric clinic, family members often worry about a possible relapse or new criminal offences, which would automatically lead back to imprisonment. The latter eventuality was a particularly strong source of anxiety.

"He is out of prison, but it is something double, because the risk exists that he will again be incarcerated. And I will not survive it a third time. [...] Waiting three years for a place in psychiatry and then be sent back to prison because of what?" (Mother) 


\subsection{Theme 5: Fight a losing battle}

Over the years, most family members learned to deal with the mental illness of their relative. However, they experienced the internment measure as unpredictable due to its indefinite duration. Family members indicated feeling sad and angry that the relative had to commit a criminal offence before legal measures were taken for mandatory treatment. Thus, they believe that the mental heath system has failed to prevent the criminal offence.

"It is not only accepting and trying as much as possible in order to deal with the disease that it makes it difficult. But frequently the confrontation with the failing of the mental health care services. I experienced it like this. I had hope that sometimes more would be done." (Mother)

In addition to this constant battle for better care and respect for their relative, many family members are also fighting for personal recognition and support.

"An equal dialogue between family, patient and social worker is an aim to strive for and to work on. As a social worker it is important to have an eye for the relationship between the client and his family and to support this." (Mother)

\subsection{Theme 6: While there is life there is hope}

Some family members felt supported by 'fellow-sufferers' they had met during their prison visits or meetings of a non-profit organization for family members of mentally ill 
persons over the years. The sharing of similar stories indicated that they were not alone and made them fell less stigmatised even though it was sometimes difficult to open up to others.

"We are sitting here as companions in adversity, all about the same thing. One even worse than the other. More painful... Pain is pain, but you notice... Yes, he is handling it like that, I am managing it like this. You are all stirring in the same jar. You receive recognition, but at the same time you make someone face the facts." (Brother)

Family members are sometimes afraid to look too far in the future and prefer to live day by day. Especially if there is no future perspective because their relative is still incarcerated or the admission in a (forensic) psychiatric hospital is not what they had hoped for. Yet, many family members maintain hope that their relative can eventually live a happy and normal life in the community.

“We have seen him become 'human' again and we hope he can be happy and can get a perspective towards the best possible life. That is like I see it, that he can be happy, but that he also can get chances, because he is not an old man." (Mother)

Family members sometimes experience a 'roller coaster of emotions', but still hope that although the mental illness may last, the internment measure will end one day.

"The entire period alternates with different feelings. But loving and adoring him as mother has never been gone. These feelings were constantly accompanied by a lot of other impressions and thoughts that are hard to describe in one sentence. To name a 
few: disbelief, astonishment, disappointment, grief, powerlessness, incomprehension of the environment causing social isolation, shame, desperation, sometimes hope if we thought or imagined there was a revolution." (Mother)

In due course, family members are sometimes able to report positive events that help them better cope with the situation. Most of these positive events are related to successful treatment of their relative, feedback from mental health professionals about their relative, a good relationship with the psychiatrist or psychologist, and the positive impact of the professional on the recovery process. These helpful events strengthen the family members and help them carry on supporting their relative. They further report personal coping strategies such as reading books, watching movies, walking, or listening to and playing music.

"I have read a lot and I think that was something that gave me grip. It was more fleeing in literature, books and so. And I also did like to watch movies." (Daughter)

"Don't take away our walking and especially not our music and our music instrument. Playing on my oboe I can get rid of my sadness, but also my anger." (Mother and father)

\section{Discussion}

This study has investigated the experiences of family members of mentally ill offenders with regard to the confrontation with the mental illness, the internment measure and the (forensic) psychiatric treatment of their relative. It reveals that family members of 
mentally ill offenders placed under an internment measure experience a double stigma, in accordance with earlier reports that mentally ill offenders are seen as both 'mad and bad', conferring a double burden on family members (Nordström et al., 2006; Tsang et al., 2002; Tsang et al., 2003). Consequently, families experience feelings of guilt and shame as they often attribute their relative's problems to themselves (e.g. parents feeling failed in the raising of their child). Sometimes they avoid disclosing their problems to friends and family and become isolated from social activities. The stigma as well as emotional and social burdens are major sources of psychological distress that can lead to social isolation (Muralidharan et al., 2014; Tsang et al., 2002; van der Sanden, Stutterheim, Pryor, Kok \& Bos, 2014). Furthermore, this isolation and not being taken seriously by other family members, friends, or mental health professionals can have a negative impact on their quality of life (Hayes et al., 2015; Ridley et al., 2014; Tsang et al., 2002; van der Sanden, Pryor, Stutterheim, Kok, \& Bos, 2016).

Family members report ambivalent feelings and frustrations towards the judicial system and the internment measure. Family members are often confronted by legal aid counsellors and lawyers handling the financial affairs of their relative whom they perceive as lacking sufficient knowledge about mental illness and the specific treatment needs of their relative. Previous studies reported that families experience additional stress and frustration in dealing with police, the courts, and the judicial system (Maclnnes, \& Watson, 2002; McCann, McKeown, \& Porter, 1996; Tsang et al., 2002).

Family members in this study reported visits to prison as burdensome and expressed hope that their relative would eventually be transferred to a (forensic) psychiatric 
hospital. Compared to previous studies, this research also focuses on the opinions and needs of family members of incarcerated mentally ill persons. Studies on imprisonment indicate that in many cases it causes a decline in family interaction and support, suggesting that relatives and the offender may benefit from strategies that focus on restoring or maintaining family ties (Hairston, 2015; McKay et al., 2016;). Family members in this study indicate that mentally ill offenders should not be incarcerated because prison is experienced as 'not the right place to be' for their relatives.

Furthermore, family members reported sorrow and anger as their relative had to offend before legal measures were taken for mandatory treatment, especially because many, in our and other studies, had a longstanding history with mental health care services and describe the treatment and relationship with mental health professionals as disappointing (Nordström et al., 2006; Pearson, \& Tsang, 2004). Indeed, many family members disclosed troubled relations with mental health professionals because they did not receive adequate information and felt they were not sufficiently involved into the treatment process. This is consistent with previous findings that families want to be engaged in the treatment of their relative by collaborating with mental health professionals. 'Medical confidentiality' is often mentioned as a barrier to contact between family members and treatment staff of their relative (Maclnnes, \& Watson, 2002; McCann et al., 1996; Ridley et al., 2014; Rowaert et al., 2016).

In the present study, many family members declared that they 'fight a losing battle' most of the time. They perceive the internment measure as troublesome because of its indefinite duration. Many family members believe that the current mental health system has failed in taking appropriate measures to prevent the criminal offence of 
their relative. The negative attitudes of family members towards the judicial and care systems often prevent them to see some positive aspects. Therefore it is often hard for them to affiliate with the systems involved. However, an important finding of this study is that some participants experience the internment measure as a starting point for help as it has led to adequate treatment for their relative. This is often experienced after years of grief and suffering, because many mentally ill offenders are first locked up in prison without adequate support or treatment.

Previous studies recommended that professionals should take more initiative to inform, educate, and support family members as well as mentally ill offenders (Nordström et al., 2006; Rowaert et al., 2016). Despite this enduring battle, families keep on fighting for their relative. The powerlessness regarding the internment measure and its infinite duration are identified as reasons to keep on fighting for recognition of the needs of their relative and themselves. Family members in this study have developed coping strategies to deal with the problems they face and draw strength by focusing on occasional positive events, such as getting feedback from professionals and the positive impact professionals have on the recovery process. Consequently, they experience renewed hope, which in previous research is mentioned as a critical source of strength (Nordström et al., 2006).

Compared to other research studies with family members of mentally ill (offenders), similar results are found. Family members experience a rollercoaster of emotions when they are confronted with a relative with mental illness placed under an internment measure. Yet, new recommendations for future research can be mentioned, as the experiences of the family members in this study underscore the need for changes in 
the treatment system of mentally ill offenders. First, family members expressed a strong desire for mechanisms to initiate mandatory treatment and support earlier in the life course of the relative, as they consider criminal offences likely to be prevented if more appropriate care is given. This relates to the concept of what is called the "bonus for delict'-mechanism, developed by De Bock already in the 1960's within the context of child protection. De Bock stated that effective treatment and care are initiated by judicial interventions, but only after the criminal offence has occurred (Verhellen, 1998). This concept is inherently paradoxical as it refers to mandatory treatment, before any (criminal) offence has taken place. Obviously, this requires careful reflection, as mandated care may have negative consequences as well. If an offence does take place, mental health care should be provided in specialized (forensic) psychiatric facilities rather than in prisons. Second, both mentally ill offenders and family members should be empowered, supported, and heard by mental health professionals early in the mental health and judicial trajectory (Ridley et al., 2014; van der Sanden et al., 2014). This could lead to more family involvement in treatment and to a mutual collaboration where families are not seen as 'second patients' needing treatment, but rather as 'partners in care'. Yet, we must be cautious not to hand over all of the care responsibility to family members, as this may neglect structural aspects related to (the lack of) professional care and support, e.g., in prison settings. Third, family members reported the value of sharing their personal stories with peers in for example peer support groups to better cope with the double stigma associated with being the family of a mentally ill offender (Gavois et al., 2006; Mokgothu, Du Plessis, \& Koen, 2015). 
The study results should be considered in light of several limitations. First, only 24 family members willing to disclose their situation were involved in the study, a sample size in the range (17 and 23 participants) of previous studies (Absalom-Hornby, Gooding, \& Tarrier, 2011; Ferriter \& Huband, 2003; McCann et al., 1996; Nordström et al., 2006; Pearson, \& Tsang, 2004). Second, the study sample may be biased because family members were recruited by a non-profit organization for family members of persons with a mental illness, many of whom suffer from schizophrenia or psychoses. Consequently, families of offenders with other mental illnesses (e.g., personality disorder, intellectual disability, etc.) may be underrepresented. Third, most of family members had a longstanding history with the mental health care system and the internment measure, so the experiences of family members recently confronted with this problematic situation were not documented. Their reticence may stem from the double stigma associated with having a mentally ill relative in the Belgian criminal justice system.

Future research should pay more attention to the experiences and needs of family members of mentally ill offenders and how they can be involved more often as 'partners in care' in the treatment of their relative. Consequently, peer support as well as mutual collaboration between mental health professionals, patients and family members is regarded essential and more research is warranted in relation to the development of family strengths and family quality of life.

\section{Acknowledgements}

The interviews in this study were carried out in cooperation with Laura Thomas and Lieze Scholberg, two master-level students in Special Needs Education (Ghent 
University). This study is part of a more comprehensive project (concerted research action - "GOA-project"), entitled: 'Developing multidisciplinary strengths-based strategies for mentally ill offenders', that is funded by the Special Research Fund of Ghent University. We would like to dedicate this article to our beloved colleague Prof. Dr. Eric Broekaert, one of the supervisors of the "GOA-project" who unexpectedly passed away recently. 


\section{References}

Abracen, J., Gallo, A., Looman, J., \& Goodwill, A. (2015). Individual CommunityBased Treatment of Offenders With Mental IIIness: Relationship to Recidivism. Journal of Interpersonal Violence, 31(10), 1842-1858. doi: 10.1177/088620515570745.

Absalom-Hornby, V.L., Gooding, P. \& Tarrier, N. (2011). Coping With Schizophrenia in Forensic Services The Needs of Relatives. Journal of Nervous and Mental Disease, 199(6), 398-402. doi: 10.1097/NMD.0b013e3182cd394.

Bal, P., \& Koenraadt, F. (2000). Criminal law and mentally ill offenders in comparative perspective. Psychology, Crime \& Law, 6(4), 219-250. doi: $10.1080 / 10683160008409805$

Bolkan, C. R., Bonner, L. M., Campbell, D. G., Lanto, A., Zivin, K., Chaney, E., \& Rubenstein, L. V. (2013). Family Involvement, Medication Adherence, and Depression Outcomes Among Patients in Veterans Affairs Primary Care. Psychiatric Services, 64(5), 472-478. doi: 10.1176/appi.ps.201200160

Braun, V., \& Clarke, V. (2006). Using thematic analysis in psychology. Qualitative Research in Psychology, 3(2), 77-101. doi: 10.1191/1478088706qp063oa

Braun, V., \& Clarke, V. (2012). Thematic analysis. In H. Cooper (Editor-inChief), APA Handbook of Research Methods in Psychology: Vol. 2. Research Designs (pp. 57-71). Washington, USA: American Psychological Association. 
De Smet, S., Van Hecke, N., Verté, D., Broekaert, E., Ryan, D., \& Vandevelde, S. (2015). Treatment and Control: A Qualitative Study of Older Mentally III Offenders' Perceptions on Their Detention and Care Trajectory. International Journal of Offender Therapy and Comparative Criminology, 59(9), 964-985. doi: 10.1177/0306624X14521129.

Ferriter, M., \& Huband, N. (2003). Experiences of parents with a son or daughter suffering from schizophrenia. Journal of Psychiatric and Mental Health Nursing, 10(5), 552-560. doi: 10.1046/j.1365-2850.2003.00624.x

Fine, M. (2002). Disruptive Voices: The Possibilities for Feminist Research. Ann Arbour: University of Michigan Press.

Gavois, H., Paulsson, G., \& Fridlund, B. (2006). Mental health professional support in families with a member suffering from severe mental illness: a grounded theory model. Scandinavian Journal of Caring Sciences, 20(1), 102-109. doi: 10.1111/j.1471-6712.2006.00380.x

Hairston, C. F. (2015). Family Ties During Imprisonment: Important to Whom and For What? Journal of Sociology \& Social Welfare, 18(1), 87-104.

Hayes, L., Hawthorne, G., Farhall, J., O’Hanlon, B., \& Harvey, C. (2015). Quality of Life and Social Isolation Among Caregivers of Adults with Schizophrenia: Policy and 
Outcomes. Community Mental Health Journal, 51(5), 591-597. doi: 10.1007/s10597015-9848-6.

Heimans, H., Vander Beken, T., \& Schipaanboord, A.E. (2015). Eindelijk een echte nieuwe en goede wet op de internering? Deel 1: De gerechtelijke fase. Rechtskundig Weekblad, 79(27), 1043-1064.

Jankovic, J., Yeeles, K, Katsakou, C., Amos, T., Morriss, R., Rose, D., Nichol, P., McCabe, R., Priebe, S. (2011). Family Caregivers' Experiences of Involuntary Psychiatric Hospital Admissions of Their Relatives - a Qualitative Study. PLOS ONE, 6(10), e25425. doi: 10.1371/journal.pone.0025425.

Maclnnes, D.L., \& Watson, J.P. (2002). The differences in perceived burdens between forensic and non-forensic caregivers of individuals suffering from schizophrenia. Journal of Mental Health, 11(4), 375-388. doi: $10.1080 / 09638230020023741$.

Melamed, Y. (2010). Mentally III Persons Who Commit Crimes: Punishment or Treatment? Journal of the American Academy of Psychiatry and the Law, 38(1), 100103.

Meysman, M. (2016). The tension between cross-border cooperation in the European Area of Freedom, Security and Justice and the fundamental rights of mentally ill offenders in detention. International Journal of Law and Psychiatry, 47, 136147. doi: $10.1016 /$ j.ijp.2016.02.018 
McCann, G., McKeown, M., \& Porter, I. (1996). Understanding the needs of relatives of patients within a special hospital for mentally disordered offenders: A basis for improves services. Journal of Advanced Nursing, 23(2), 346-352. doi: 10.1111/j.1365-2648.1996.tb02677.x

McKay, T., Comfort, M., Lindquist, C., \& Bir, A. (2016). If Family Matters Supporting Family Relationships During Incarceration and Reentry. Criminology and Public Policy, 15(2), 529-542. doi: 10.1111/1745-9133.12209.

Mokgothu, M.C., Du Plessis, E., Koen, M.P. (2015). The strengths of families in supporting mentally ill family members. Curationis, 38(1), Art. \#1258, 1-8. doi: 10.4102/curationis.v38i1.1258.

Morgan, R. D., Flora, D. B., Korner, D. G., Mills, J. F., Varghese, F., Steffan, J. S. (2012). Treating Offenders With Mental IIIness: A Research Synthesis. Law and Human Behavior, 36(1), 37-50. doi: 10.1037/h0093964.

Mortelmans, D. (2011). Kwalitatieve analyse met Nvivo. Leuven, Belgium: Acco

Muralidharan, A., Lucksted, A., Medoff, D., Juan Fang, L., \& Dixon, L. (2014). Stigma: a Unique Source of Distress for Family Members of Individuals with Mental Illness. Journal of Behavioral Health Services \& Research, 43(3), 484-493. doi: 10.1007/s11414-014-9437-4. 
Nordström, A., Kullgren, G., \& Dahlgren, L. (2006). Schizophrenia and violent crime: The experience of parents. International Journal of Law and Psychiatry, 29(1), 57-67. doi: 10.1016/j.jijp.2004.07.002.

Pearson, V., \& Tsang, H.W.H. (2004). Duty, burden, and ambivalence: Families of forensic psychiatric patients in Hong Kong. International Journal of Law and Psychiatry, 27(4), 361-374. doi: 10.1016/j.ijlp.2003.08.001

Peterson, J. K., Skeem, J., Kennealy, P., Bray, B., \& Zvonkovic, A. (2014). How often and how consistently do symptoms directly precede criminal behavior among offenders with mental illness? Law and Human Behavior, 38(5), 439-449. doi: org/10.1037/lhb0000075

QSR International Pty Ltd. (2015). Nvivo 11 (11.2) [Software]. Geraadpleegd van: http://www.qsrinternational.com/product/nvivo11-for-windows/pro.

Ridley, J., McKeown, M, Machin, K., Rogengard, A., Little, S., Briggs, S, Jones, F., \& Deypurkaystha, M. (2014). Exploring Family Caregiver Involvement in Forensic Mental Health Services. Scotland: Support in Mind Scotland, University of Central Lancashire and Froensic Menal Health Services Managed Care Network, pp. 1-87.

Rowaert, S., Vandevelde, S., Lemmens, G., Vanderplasschen, W., Vander Beken, T., Vander Laenen, F., \& Audenaert, K. (2016). The role and experiences of family members during the rehabilitation of mentally ill offenders. International Journal of Rehabilitation Research, 39(1), 11-19. doi: 10.1097/MRR.0000000000000152 
Sarteschi, C. M. (2013). Mentally III Offenders Involved With the U.S. Criminal Justice System: A Synthesis. Sage open, 1-11. doi: 10.1177/2158244013497029.

Sheehy, K., Rehberger, T., O'Shea, A., Hammond, W., Blais, C., Smith, M., Preston White, K. Jr., \& Goodloe, N. (2016). Evidence-Based Analysis of Mentally III Individuals in the Criminal Justice System. IEEE Systems and Information Engineering Design Symposium (SIEDS). Charlottesville, VA: IEEE (pp. 250-254).

Tsang, H.W.H., Pearson, V., \& Yuen, C.H. (2002). Family needs and burdens of mentally ill offenders. International Journal of Rehabilitation Research, 25(1), 25-32.

Tsang, H.W.H., Tam, P.K.C., Chang, F., \& Chang, W.M. (2003). Sources of burdens on families of individuals with mental illness. International Journal of Rehabilitation Research, 26(2), 123-130. doi: 10.1097/01.mrr.0000070761.13531.a1

To, W.T., Vandevelde, S., Soyez, V., De Smet, S., Boers, A. \& Vanheule, S. (2014). Treatment perspectives on interned mentally ill offenders in a forensic psychiatric center (FPC): A Delphi study on experts' opinions. Psychology, Crime \& Law, 20(1), 61-77. doi: 10.1080/1068316X.2012.736511.

Vander Beken, T., Heimans, H., \& Schipaanboord, E. (2016). Eindelijk een echte nieuwe en goede wet op de internerng? Deel 3: De reparatie. Rechtskundig Weekblad, 80(16), 603-619. 
van der Sanden, R.L.M., Stutterheim, S.E., Pryor, J.B., Kok, G., \& Bos, A.E.R. (2014). Coping With Stigma by Association and Family Burden Among Family Members of People With Mental Illness. The Journal of Nervous and Mental Disease, 202(10), 710-717. doi: 10.1097/NMD.0000000000000189.

van der Sanden, R.L.M., Pryor, J.B., Stutterheim, S.E., Kok, G., \& Bos, A.E.R. (2016). Stigma by association and family burden among family members of people with mental illness: the mediating role of coping. Social Psychiatry and Psychiatric Epidemiology, 51(9), 1233-1245. doi: 10.1007/s00127-016-1256-x

Vandevelde, S., Soyez, V., Vander Beken, T., De Smet, S., Boers, A., \& Broekaert, E. (2011). Mentally ill offenders in prison: The Belgian case. International Journal of Law and Psychiatry, 34(1), 71-78. doi: 10.1016/j.jilp.2010.11.011

Verhellen, E. (1998). Jeugdbeschermingsrecht. Gent: Mys \& Breesh 